\title{
Impact of dry density, saturation, and confinement on gas permeability of clay-barrier materials
}

\author{
Bohan Zhou ${ }^{1}$, Marcelo Sanchez ${ }^{2}$, and Maria Victoria Villar $^{3}$ \\ ${ }^{1}$ Zachry Department of Civil and Environmental Engineering, Texas A\&M University, College Station, Texas, USA \\ ${ }^{2}$ Zachry Department of Civil and Environmental Engineering, Texas A\&M University, College Station, Texas, USA \\ ${ }^{3}$ CIEMAT, Centro de Investigaciones Energéticas, Medioambientales y Tecnológicas, Madrid, Spain
}

\begin{abstract}
The safe isolation of high-level radioactive waste from the human environment is a key requisite in the nuclear fuel cycle. Deep geological repositories (i.e. $>500 \mathrm{~m}$ ) in a suitable rock mass, involving both engineered and natural barriers is currently the most favoured option for the disposal of high-level nuclear waste. Complex Thermal-Hydro-Mechanical and Chemical (THMC) phenomena are anticipated during the repository lifetime. The formation of gasses (e.g., as a result of oxidation processes) and their possible migration through the engineered barrier system (EBS) could jeopardise the main barrier functions. This paper focuses on the experimental study of the gas flow process through clay-barrier materials, particularly on the effect of degree of saturation, clay initial dry density, and confinement stress on gas permeability. It is shown that the initial dry density of the clay has a significant impact on gas flow, especially at low saturations. As expected, lower gas permeability values were obtained near saturation. Confinement has a minor impact on gas flow, at least for the range of stresses investigated in this paper.
\end{abstract}

\section{Introduction}

The final and safe disposal of high-level nuclear waste (HLW) is a problem that still needs to be solved. Current efforts in this area focus on the design of repositories for HLW in deep geological media. This type of disposal envisages a system of galleries excavated in good qualities rocks (e.g. salt rocks, crystalline rocks, or claystone) around $500 \mathrm{~m}$ (or deeper) below the ground level. Figure 1 presents the main components of a typical design of a deep geological repository for HLW in granite proposed by the Swedish Nuclear Fuel and Waste Management Company (SKB), which comprises: a metallic container (encapsulating the nuclear waste), a compacted clay barrier (filling the empty space between the canister and the borehole), horizontal galleries (connecting the vertical boreholes), vertical shafts and tunnels (used to access to the gallery system).

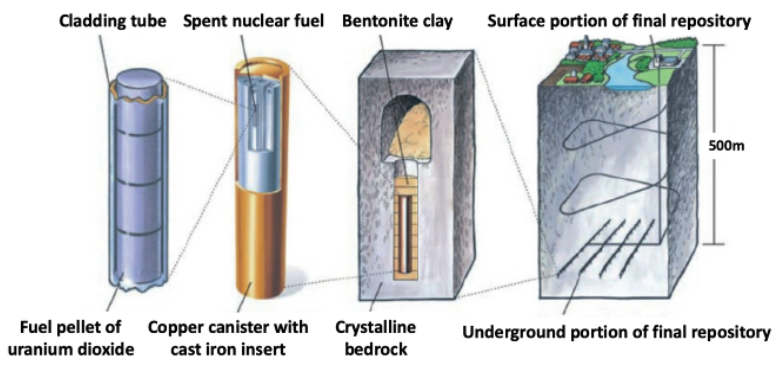

Fig. 1. A typical design concept for the disposal of HLW [1].
The engineered barrier is generally made up of compacted unsaturated bentonite. Other designs proposed for the isolation HLW in crystalline rocks envisage placing the nuclear waste in horizontal galleries [2]. More details about different options and materials that are being considered for the storage of HLW in geological media can be found elsewhere [3]. The main safety functions of the engineered barrier system (EBS) is to confine the highly pollutant waste for a very long time (i.e., hundred thousand of years), provide mechanical stability to the canister containing the HLW, delay the water flow from the host rock to the canister, serve as a buffer around the canister, and prevent the transport of radionuclides to the host rock.

Complex Thermo-Hydro-Mechanical and Chemical (THMC) phenomena will take place in the repository near field because of the simultaneous heating (coming from the radioactive decay process of the nuclear waste) and the natural hydration (arising from the host-rock) under highly confined conditions. Several experimental studies have been focused on the THM behavior of clay barrier materials (e.g., $[4,5,6]$ ), also, coupled THM numerical models have been proposed to analyze the performance of EBS under different conditions (e.g., [7, 8]). Significant progresses have been made in this subject during the last few years, and a better understanding of the main THM phenomena that control the response of these complex systems has been achieved. However, the migration of gas through the EBS is a topic that has received relatively less attention.

\footnotetext{
* Corresponding author: msanchez@civil.tamu.edu
} 
Under repository conditions the formation of gas can be anticipated. Gas will form during the repository lifetime triggered by several physical and chemical processes (e.g. metal corrosion, water radiolysis, biodegradation). Gas generation and accumulation under confined conditions will increase the gas pressure inside the EBS inducing gas flow through the barrier, process that may jeopardize the safety functions discussed above. For example, figure 2 presents the predicted hydrogen $\left(\mathrm{H}_{2}\right)$ partial-pressure evolution in the bentonite associated with the canister corrosion. $\mathrm{H}_{2}$ pressure reaches a peak after 5104 years, with a maximum pressure around $16200 \mathrm{~atm}$ (based on a corrosion rate of $\left.2 \mu / y^{[9]}\right)$. A decrease of the pressure is observed after the canister is fully corroded. Similar results have been reported in other studies.

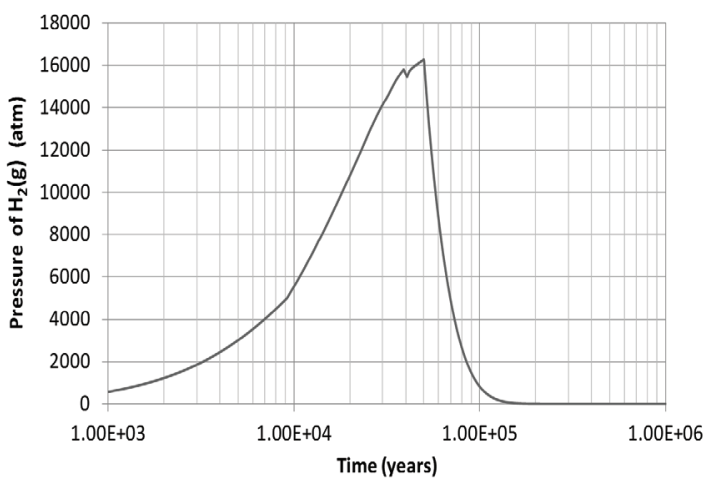

Fig. 2. Predicted evolution of $\mathrm{H}_{2}$ partial pressure induced by canister corrosion [9]

There have been recent research efforts worldwide aimed at improving the current understating of gas accumulation and flow processes through EBS, such as, the: "Fate of Repository Gases (FORGE)" project, which is funded by the European Commission (e.g., [10]). In the USA, the research project "Impact of coupled gas migration and thermo-hydro-mechanical processes on the performance of repositories for high level nuclear waste" funded by Nuclear Energy University Program (NEUP), Department of Energy (DOE) investigates the gas flow through EBS [11]. This paper presents results from this project related to gas permeability tests conducted on specimens of a compacted bentonite intended as barrier materials for the disposal of HLW. Particular attention is paid to the effect of the sample initial dry density, degree of saturation and confinement on gas permeability. These experiments focused on gas flow through the 'intact' compacted clay, results related to the gas migration through clayed-materials discontinuities (drying cracks) and interfaces between dissimilar materials are presented in [12] and [13], respectively.

\section{Material}

The MX-80 sodium bentonite from the American Colloid Company in Wyoming (USA) was adopted in this research for the experimental campaign. Several key properties of this clay make it a very appropriate barrier material, namely, extremely low permeability, selfhealing ability, low ion transport capacity, high chemical stability, and high swelling potential [14]. This is why the MX- 80 bentonite has been adopted in several research projects aimed at investigating the performance of EBS in the context of HLW disposal (e.g. $[15,16])$.

The average particle size ranges between sieves \#40 and $\# 200$. The hygroscopic water content $(w)$ of this clay under laboratory condition is around $11 \%$. The specific gravity (Gs) is 2.8. Figures $3 \mathrm{a}$ and $3 \mathrm{~b}$ correspond to pictures of MX-80 clay in powder and (statically) compacted states, respectively.

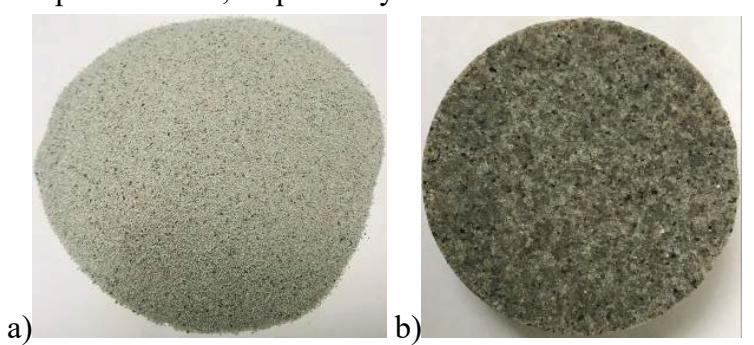

Fig. 3. MX-80 sodium bentonite, a) powder, and b) compacted unsaturated sample.

\subsection{Atterberg limits}

The Liquid Limit (LL) was obtained using the Casagrande method according to the ASTM D4318 [17]. The tests were repeated three times with an average value of $L L=295$. The determination of the Plastic Limit (PL) was conducted using the rolling thread method as stablished in the ASTM D4318. The average result of three test was $\mathrm{PL}=55$. Therefore, the Plasticity Index (PI) of the MX-80 bentonite used in this study is $\mathrm{PI}=240$.

\subsection{Compaction curves}

Although the current design of EBS is based on clayey materials statically compacted, this work also investigates the behavior of the MX- 80 bentonite when is dynamically compacted. Both standard and modified compaction tests were conducted according to the ASTM D698 [18].

Figure 4 presents the main result obtained from the compaction tests, together with zero air void curve. It is evident that it could be difficult to achieve the relatively dense packing generally required in the construction of EBS by dynamic compaction. It is also apparent that the MX-80 clay presents a double peak pattern in the compaction curve, which is more evident when compacted at low compaction energy. This behavior can be associate with both, the stiff character of the clayaggregates that are formed at low saturations, and the high friction developed between them. These two factors prevent an effective compaction of the sample. As the water content increases, the compaction effort is more efficient, because the inter-aggregates friction decreases, and also the aggregates become more deformable. This double peak phenomenon is explained in detailed in [19]. 


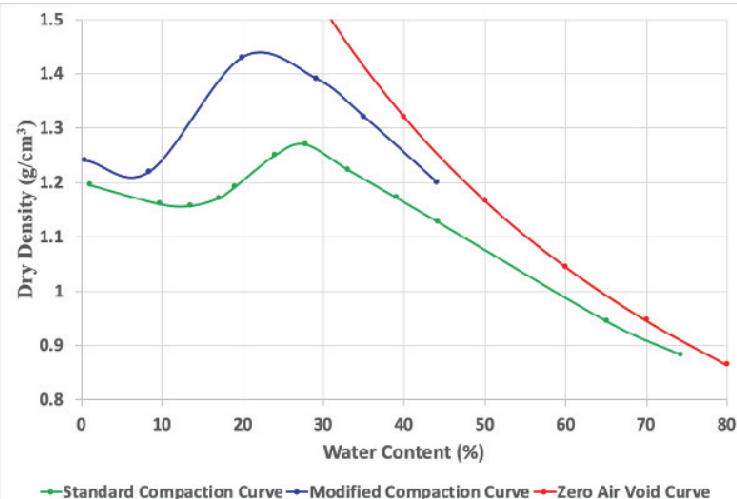

Fig. 4. Results from the compaction tests.

\subsection{Sample preparation}

The samples investigated in this work were statically compacted to mimic the clay condition anticipated during the construction of EBS. The specimens were compacted in a load frame inside a stiff metallic mold that prevented the lateral deformation of the sample and minimized the soil-mold friction. Two initial dry densities $\left(\rho_{d}\right)$ were adapted in this research, namely: $\rho_{\mathrm{d}}=1.30 \mathrm{~g} / \mathrm{cm}^{3}$ and $\rho_{\mathrm{d}}=1.60 \mathrm{~g} / \mathrm{cm}^{3}$.

A total of eleven samples at $\rho_{\mathrm{d}}=1.6 \mathrm{~g} / \mathrm{cm}^{3}$ were prepared at different saturation degrees $\left(\mathrm{S}_{\mathrm{r}}\right)$, namely: $S_{r}=$ $97 \%, S_{r}=90 \%, \quad S_{r}=80 \%, \quad S_{r}=70 \%, \quad S_{r}=60 \%, \quad S_{r}=50 \%$, $S_{r}=40 \%, S_{r}=30 \%, S_{r}=20 \%, S_{r}=10 \%$, and $S_{r}=0 \%$. As for $\rho_{\mathrm{d}}=1.3 \mathrm{~g} / \mathrm{cm}^{3}$, eight specimens were prepared, namely: $S_{r}=97 \%, S_{r}=90 \%, S_{r}=80 \%, S_{r}=70 \%, S_{r}=60 \%, S_{r}=50 \%$, $S_{r}=40 \%$, and $S_{r}=30 \%$. Note that it was not possible to investigate samples at $\rho_{\mathrm{d}}=1.3 \mathrm{~g} / \mathrm{cm}^{3}$ and low saturations (i.e. $S_{r}<30 \%$ ), because the samples broken during tests

The sample preparation involved the mixing of the (dry) clay powders with water until achieving the desired initial $S_{r}$ values. The wetted specimens were then sealed in plastic bags for a period of 24hours to achieve moisture homogenization. Then, the clay was statically compacted up to the target sample size (i.e., $3.5 \mathrm{~cm}$ in diameter, and $1.4 \mathrm{~cm}$ in height) using a load frame (as discussed above). The samples were then extruded and moved to the automated GEOTAC triaxial cell to conduct the gas permeability test under controlled conditions, as explained in Section 3.

\subsection{Soil water retention curve}

The soil water retention curve (SWRC) relates the saturation degree with suction. To cover a wide range of suctions, the WP4 [20] and the filter paper methods (ASTM D5298-10, [21]) were combined in the determination of the SWRCs for the two dry densities adopted in this research.

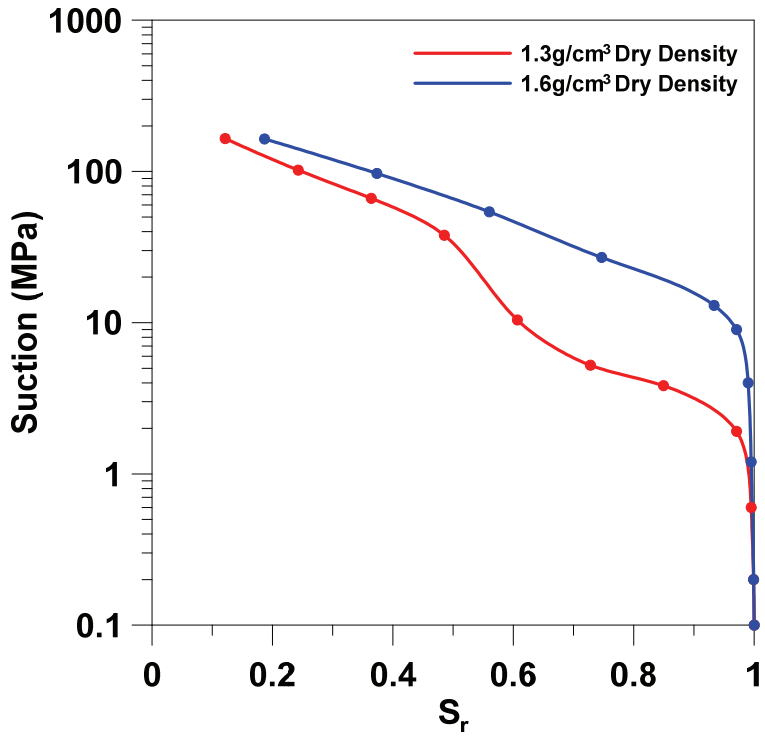

Fig. 4. Experimental soil water retention curves for the specimens compacted at the two dry densities investigated in this research.

\section{Gas permeability test protocol}

The gas permeability tests were conducted using an upgraded GEOTAC TruePath triaxial cell. This automated stress path system consists of a Sigma-1 load frame, two Digi-Flow pressure volume actuators (i.e. flow pumps), and a high-resolution analog data acquisition system. These components are connected to a computer through TestNet. A high-precision mass flowmeter was incorporated to measure the gas outflow. To prevent the presence of wet air (and water drops) passing through the flowmeter a liquid filter (water trap) from Swagelok was connected just before the flowmeter. To study the gas permeability under different confinements, two cell pressures (CP) were adopted, namely: $\mathrm{CP}=0.35 \mathrm{MPa}$ and $\mathrm{CP}=0.70 \mathrm{MPa}$. The picture in Figure 5 shows the setup adopted to conduct the gas permeability tests.

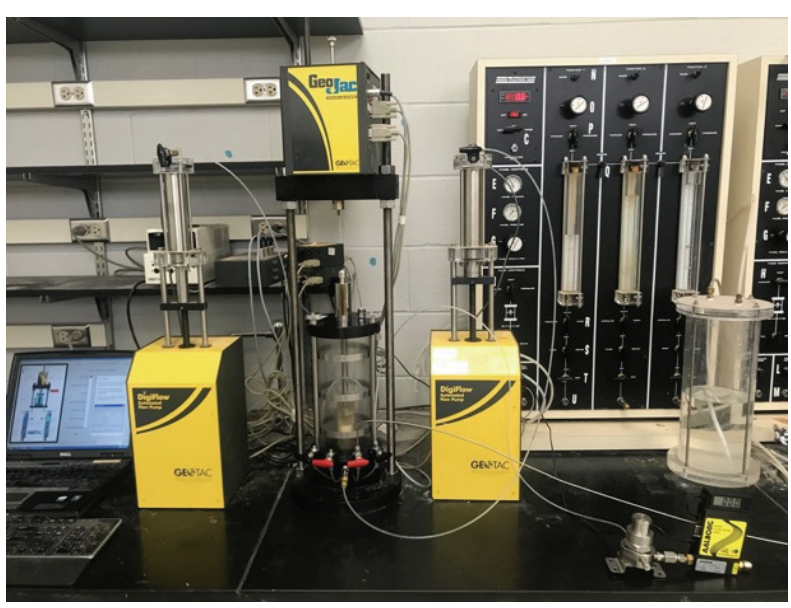

Fig. 5. Picture showing the setup for gas permeability tests. 
Figure 6 presents a general schematic representation of the adopted setup to conduct the permeability tests including the gas tanks; regulator and manometer; inlet and outlet valves; triaxial cell with the clay specimen; water trap; and flowmeter.

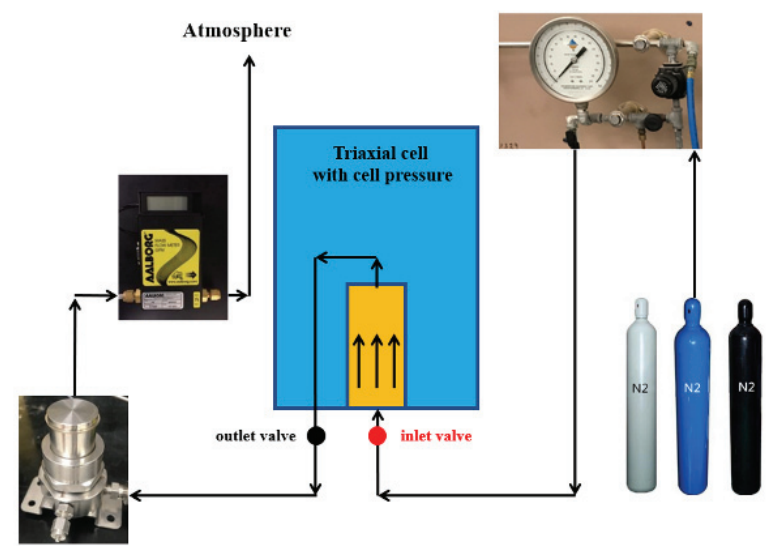

Fig. 6. Schematic representation of the adopted setup to conduct the gas permeability tests.

Nitrogen was the gas was adopted to conduct the test and a steady state method was selected to determine the gas permeability using the following equation (e.g., [22]):

$$
K_{g}=\frac{Q \times \mu \times L \times 2 P_{m}}{A \times\left(P_{u p}^{2}-P_{d o w n}^{2}\right)}
$$

where $\mathrm{Q}$ is the flow rate; $\mathrm{L}$ is sample length ; $\mu$ is the viscosity of the nitrogen gas; $\mathrm{A}$ is the cross section area of the sample; $\mathrm{P}_{\mathrm{m}}$ is pressure at the measurement side, $\mathrm{P}_{\text {up }}$ and $\mathrm{P}_{\text {down }}$ are the upstream and downstream pressures, respectively.

The protocol adopted to measure the gas permeability is based on previous experiences in this area reported in the literature (e.g. $[22,23,24,25$, and 26]). The main stages of the adopted procedure are summarized as follows:

(1) Sample preparation at the target values of $S_{r}$ and $\rho_{\mathrm{d}}$

(2) Sample setup in the triaxial cell and triaxial chamber filled with distilled water.

(3) Connect cell pressure pipes, gas-in and gas-out pipes, water trap, and mass flowmeter;

(4) Fix the cell pressure using the hydraulic pump, open the flow-in and flow-out valves, and inject the gas.

(5) Upstream gas pressure (i.e., measured from the pressure gauge on regulator) and the gas outflow (i.e., obtained from mass flowmeter) are recoded once they are stable.

(6) Dismantle the sample and follow the same steps to conduct the next test at a different $S_{r}$ or $\rho_{\mathrm{d}}$.

\section{Results}

Figure 7 presents the results of the gas permeability tests on MX-80 clay samples prepared at different saturation degrees, dry densities, and confined at different cell pressures. As expected, for a given confinement and saturation degree the specimens prepared at a higher dry density $\left(1.6 \mathrm{~g} / \mathrm{cm}^{3}\right)$ are less permeable to gas than the ones compacted at a lower dry density sample $\left(1.3 \mathrm{~g} / \mathrm{cm}^{3}\right)$. This behavior is directly related to the difference in the porosity of these specimens. It is also observed that the clay moisture strongly impacts on gas permeability. An (almost) blocking of the gas permeability is observed when $S_{r}>75 \%$, in tests conducted on samples at $\rho_{\mathrm{d}}=1.6 \mathrm{~g} / \mathrm{cm}^{3}$, whereas this blocking effect is observed when $S_{r}>90 \%$ when the $\rho_{\mathrm{d}}=1.3 \mathrm{~g} / \mathrm{cm}^{3}$. For the range of stresses investigated in this work, it is observed that the confinement has practically no effect on the gas permeability.

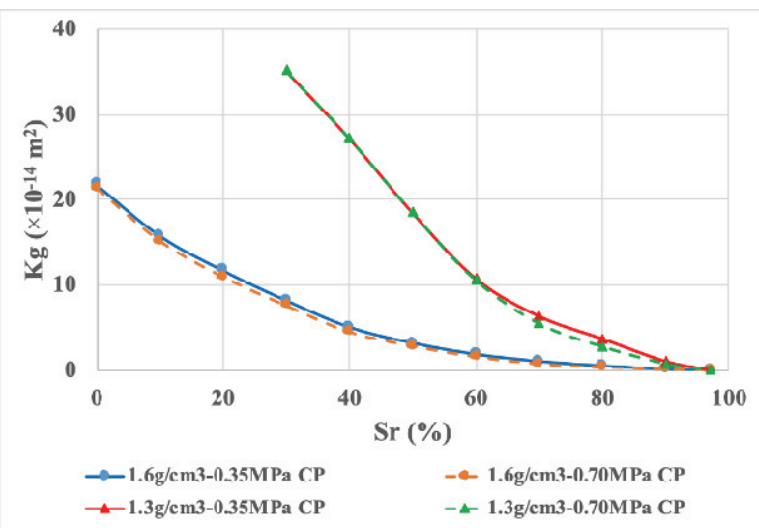

Fig. 7. Results of gas permeability experiments involving samples prepared at different dry densities, saturation and tested under different confinement conditions.

\section{Summary and Conclusions}

Gas generation, accumulation, and possible migration in repositories for high-level nuclear waste can jeopardize the main safety functions of the engineered barrier system envisaged to isolate the highly pollutant waste from the biosphere. Gas can flow through the compacted clay or through preferential pathways in the EBS, in the form of material discontinuities (e.g. drying cracks), or interfaces between dissimilar materials (e.g., at the clayrock contact). This experimental research focuses on the gas permeability of samples prepared from unsaturated bentonite compacted at two different dry densities. The effect of liquid saturation and confinement is also investigated using a steady state method to measure the gas permeability. It is observed that initial dry density and liquid saturation have a strong impact on gas permeability, whereas confinement plays a minor role, at least for the range of stresses investigated in this research

The financial support from NEUP-DOE, USA, Award DENE0008762 (Project \#18-15585) is acknowledged. 


\section{References}

1. SKB. Report of the Site project I-III (2011).

2. A. Gens, M. Sánchez, L. Guimaraes, E. Alonso, A. Lloret, S. Olivella, M.V. Villar, F. Huertas. 2009. A full scale in situ heating test for high level nuclear waste disposal. Observations, analysis and interpretation. Géotechnique, 59(4): 377-399. (2009)

3. J-S. Kim, S-K. Kwon, M. Sanchez, G-Ch, Cho. Geological storage of high-level nuclear waste. KSCE Journal of Civil Engineering, 15(4): 721-737. (2011)

4. A. Lloret, M.V. Villar, M. Sánchez, A. Gens, X. Pintado, E. Alonso. Mechanical behaviour of heavily compacted bentonite under high suction changes. Géotechnique; 53(1): 27-40. (2003)

5. P. Delage, T-T. Le, A-M. Tang, Y-J. Cui, X-L. Li. Suction effects in deep Boom clay block samples. Géotechnique. 57 (2), 239-244. (2007)

6. M. Villar, M. Sánchez, A. Gens. Behaviour of a bentonite barrier in the laboratory: Experimental results up to 8 years and numerical simulation. Phys. and Chem. of the Earth 33, S476-S485 (2008).

7. H. Thomas, P. Cleall, J. Dixon, and H. Mitchell. The coupled thermal - hydraulic - mechanical behaviour of a large scale in-situ heating experiment. Géotechnique, 59(4), 401-413 (2009).

8. M. Sánchez, A. Gens, L. Guimarães. Thermalhydraulic-mechanical (THM) behaviour of a largescale in situ heating experiment during cooling and dismantling. Can. Geotech. J., 49(10), 1169-1195. (2012).

9. EBS report. Project deliverable 3.5-3. 2014. EC Euroatom 7. (2012).

10. R. Shaw. The Fate of Repository Gases (FORGE) project. Geological Society, London, Special Publications, 415, 1-7, 23 (2015).

11. Project: Impact of coupled gas migration and thermo-hydro-mechanical processes on the performance of repositories for high level nuclear waste, Nuclear Energy University Program (NEUP), Department of Energy (DOE). Retrieved from https://sites.google.com/view/doe-project/homepage

12. M. Ali-Falak, M. Sanchez, E. Romero-Morales. Gas Migration Phenomena Through Interfaces in Engineering Barrier Systems. Contribution ID: 33157. 2020 ANS Virtual Winter Meeting. November 16-19 (2020).

13. B. Zhou, M. Sanchez. Effect of Heating and Drying on Clay-Barrier Gas-Permeability. Winter ANS Meeting. Contribution ID: 331602020 ANS Virtual Winter Meeting. November 16-19 (2020).

14. J.F. Liu, F. Skoczylas, C. Davy. Sealing efficiency of an argillite-bentonite plug subjected to gas pressure, in the context of deep underground radioactive waste storage. FORGE Report D3-08; D3-24, D3-30 and D3-35 (2013).
15. R. Pusch, H. Hökmark, L. Börgesson. Outline of models of water and gas flow through smectite clay buffers. SKB Technical Report 87-10, Stockholm, Sweden (1987).

16. S. Horseman, J. Harrington, P. Sellin. Water and gas flow in Mx80 bentonite buffer clay. Materials Research Society, 807, 715-720 (2004).

17. ASTM D4318. Standard Test Methods for Liquid Limit, Plastic Limit, and Plasticity Index of Soils

18. ASTM D698. Standard Test Methods for Laboratory Compaction Characteristics of Soil Using Standard Effort

19. G. El Mountassir, M. Sanchez, E. Romero. An experimental study on the compaction and collapsible behaviour of a flood defence embankment fill. Engineering Geology. 179, 132145 (2014).

20. Decagon Devices, Inc. Dewpoint Potentiometer for models WP4 and WP4-T. Operator's Manual, Version 5. (2007). Retrieved from http://www.ictinternational.com/content/uploads/20 17/04/WP4-Operators-Manual.pdf.

21. ASTM D5298-10. Standard Test Method For Measurement Of Soil Potential (Suction) Using Filter Paper

22. M.V. Villar, V. Gutierrez-Rodrigo, P.L. Martin, F.J. Romero, J.M. Barcala. Ciemat Report 1301 (2013).

23. C. Galle, K. Tanai. Evaluation of gas transport properties of backfill materials for waste disposal: H2 migration experiments in compacted Fo-Ca Clay Clays Clay Minerals. 46, 498-508 (1998).

24. J.F. Liu, F. Skoczylas, J. Talandier. Gas permeability of a compacted bentonite-sand mixture: coupled effects of water content, dry density, and confining pressure. Can. Geotech. J., 52(8), 1159 (2015).

25. T. Wei, D. Hu, H. Zhou, J. Lu, T. Lü. Influences of degree of saturation and stress cycle on gas permeability of unsaturated compacted Gaomiaozi bentonite. Eng. Geo. 254, 54-62 (2019).

26. J. Joseph, G. Kuntikana, D.N. Singh. Investigations on gas permeability in porous media. Jnl. of Nat. Gas Sci. and Eng., 64, 81-92 (2019). 